\title{
Salivary glucose in monitoring glycaemia in patients with type 1 diabetes mellitus: a systematic review
}

\author{
Cho Naing ${ }^{*}$ and Joon Wah Mak
}

\begin{abstract}
Background: Incidence of type 1 diabetes mellitus is increasing worldwide. Monitoring glycaemia is essential for control of diabetes mellitus. Conventional blood-based measurement of glucose requires venepuncture or needle prick, which is not free from pain and risk of infection. The non-invasiveness, ease and low-cost in collection made saliva an attractive alternative sample. The objective of this review was to systematically review the evidence on the relationship between salivary glucose level and blood glucose level in monitoring glycaemia in patients with type 1 diabetes mellitus.

Methods: We searched studies which evaluate salivary glucose levels and serum glycaemia in type 1 diabetes mellitus in electronic databases of MEDLINE, EMBASE, Ovid and Google Scholar. We selected the eligible studies, following the inclusion criteria set for this review. Due to heterogeneity of studies, we conducted qualitative synthesis of studies.

Results: Ten observational studies were included in this review, including a total of 321 cases and 323 controls with ages between 3 and 61 years and the majority were males (62\%). Two studies were done exclusively on children below 17 years old. The significant difference between salivary glucose levels in type 1 diabetes mellitus and controls were reported in 6 studies with 8 data sets. Five studies with 7 datasets reported the correlation coefficient between salivary glucose and blood glucose in patients with diabetes.
\end{abstract}

Conclusions: Findings suggest that salivary glucose concentrations may be helpful in monitoring glycaemia in type 1 diabetes mellitus. However, the utility of using salivary glucose level to monitor glycaemia should be evaluated in future well designed, prospective studies with adequate number of participants with type 1 diabetes mellitus.

Keywords: Diabetes mellitus, Diagnosis, Glucose, Saliva, Systematic review

\section{Background}

Diabetes mellitus, a group of metabolic diseases characterized by chronic hyperglycaemia resulting from defects in insulin secretion, insulin action, or both can be broadly categorized into type 1 diabetes mellitus (destruction of pancreatic beta cells, causing absolute deficiency of insulin), type 2 diabetes mellitus (a combination of decreased insulin secretion and decreased insulin sensitivity (i.e. insulin resistance) [1], gestational diabetes mellitus [2], other specific types of diabetes mellitus - monogenic diabetes mellitus/maturity onset diabetes of the young,

\footnotetext{
* Correspondence: cho3699@gmail.com

Institute for Research, Development and Innovation (IRDI), International Medical University, Kuala Lumpur 57000, Malaysia
}

genetic defects of beta-cell function or insulin action, diseases of pancreas, drug induced or associated with genetic syndromes and others (i.e. monogenic mutation in chromosome 12 or $7 \mathrm{p}$, mitochondrial DNA, cystic fibrosis, hemochromatosis, endocrinopathies etc.) [1]. The incidence of type 1 diabetes mellitus is increasing worldwide both in low and high income populations [3]. Type 1 diabetes mellitus can affect people of any age, but usually occurs in children or young adults [1], the age group whose learning and earning potentials and capacities are crucial for the welfare of family and society at large.

Studies have documented that normalization of blood glucose levels can result in regression of diabetes associated complications such as peripheral neuropathy and 
peripheral vascular disease [4]. Repeated monitoring of plasma glucose in people with diabetes mellitus helps with timely identification of hyperglycaemia and is crucial for prevention of such devastating complications that can arise from poor control of the disease. The conventional method of blood-based investigations involve invasive procedures for blood sample collections from patients. This could evoke needle anxiety or a risk of blood-borne infections or both. Studies have shown that prevalence of needle anxiety in paediatric patients was $27 \%$ [5] and $22 \%$ of all patients of all ages in general practices [6]. Fear of sharp objects (needle) could further discourage some patients from monitoring their blood sugar levels regularly. It has been documented that $20.5 \%$ of those who reported needle anxiety avoided medical treatment involving needles [6].

Published studies have indicated the possible utility of saliva in monitoring of uric acid for cardiometabolic risk [7], drugs such as theophylline and steroids, quantitation of viral nucleic acids in herpes simplex virus DNA, varicella zoster virus DNA, and hepatitis C virus RNA [8], identification of biomarkers (IL- $1 \beta,-6,-8$, TNF- $\alpha$, lysozyme, MMP8 , TIMP-1) and total protein concentration in systemic diseases [9], inter alia. The non-invasiveness, ease and lowcost in collection have made saliva an attractive sample.

There has been a surge in published studies on the usefulness of saliva for monitoring of glycaemia. Some studies showed that salivary glucose levels were high in type 1 diabetes mellitus compared to controls [10] or were positively related to serum glucose in patients with diabetes, albeit with variation in the magnitude of relationships. Some studies reported differently [11, 12]. We are aware of the reviews looking at the usefulness of salivary glucose to monitor glycaemia in type 2 diabetes mellitus [13] or non-specified diabetes mellitus [14, 15]. Although all forms of diabetes mellitus are characterised by hyperglycaemia, their aetiology and pathogenesis vary. Acute, long-term and post-prandial hyperglycaemia are some of the conditions associated with endothelial dysfunction in type 1 diabetes mellitus [16]. Secretory activity of many exocrine glands (including salivary glands) depend on blood flow to these glands which in turn might depend on endothelial production of nitric oxide. Taken together, attention to the usefulness of saliva in monitoring of glycaemia in type 1 diabetes mellitus is valuable. The objective of the current review was to systematically review the evidence on the relationship between salivary glucose level and blood glucose level in monitoring glycaemia in patients with type 1 diabetes mellitus.

\section{Methods}

We conducted this systematic review, following the guideline for the preferred reporting items of systematic review and meta-analysis (PRISMA) [17].

\section{Literature search}

We searched studies which evaluate salivary glucose levels and serum glycaemia in type 1 diabetes mellitus in electronic databases of MEDLINE, EMBASE Ovid and Google Scholar. Search terms for studies were identified through medical subject headings $(\mathrm{MeSH})$ as well as from those used for systematic reviews in similar context. MeSH terms and text words used were "saliva AND glucose" "sugar AND saliva" "saliva AND glycaemia" "diabetes AND saliva", "saliva AND glycaemia", "IDDM AND glycaemia" and "type 1 diabetes AND glycaemia". The search was limited to publications in English language up to August 2016. We also manually checked the reference sections of the selected studies and relevant reviews for the possibility of any additional studies that might have been missed by the electronic search.

\section{Study selection}

Studies were included if they were observational studies (survey, cross-sectional, case-control, cohort) carried out with minimum 10 participants of type 1 diabetes mellitus, regardless of age, gender and pregnant state and assessed correlation between salivary glucose concentration and blood sugar level in the same patient, compared mean salivary glucose levels between those with type 1 diabetes mellitus and healthy controls or those without diabetes mellitus.

Studies were excluded if they did not meet the inclusion criteria or assess participants with other comorbid diseases, which can alter salivary gland functions. Diabetes mellitus was confirmed (i) by self-report of patients with supportive medical records, (ii) as per the criteria by the expert committee on diagnosis and classification of diabetes mellitus [2], or (iii) by the American Diabetes Association (ADA) standards of medical care in diabetes [18].

\section{Data extraction from studies}

One author $(\mathrm{CN})$ screened titles and abstracts identified according to the selection criteria set for this review and this was cross-checked by the second assessor (JWM). The two authors then independently retrieved full-text copies of all articles that might be potentially relevant. The two authors then collected data from each study using a piloted spreadsheet. Data collected were author, year of publication, study country and setting, study design, original purposes, sample size, saliva collection, methods of glucose estimation and main outcome. The methodological quality of primary studies was assessed using the Newcastle-Ottawa Scale (NOS) [19]. The instrument used a star system to assess the study quality and the highest total score for a study that could be achieved was nine. During these processes, any discrepancy 
between the two authors was resolved by reaching a consensus by discussion.

\section{Statistical analyses}

The studies identified for the current review used different outcome measures. As such, a variety of transformations were required to estimate the effect sizes [20,21]. When studies reported 'correlation coefficients' between salivary glucose and blood glucose levels in persons with type 1 diabetes mellitus, we made transformation into approximate normality based on Fisher's $z$ score. If the correlation coefficient was not reported, we estimated Fisher's $z$ score from the $t$ statistic of the linear association between salivary glucose and blood glucose. When studies reported the mean differences $( \pm$ standard deviation, SD) of saliva glucose and blood glucose levels in type 1 diabetes mellitus and controls or non- diabetes mellitus, effect sizes for continuous measures were appropriate to apply. We considered Hedge's standardized mean difference $g$ as an effect size index described elsewhere [21-23]. Due to substantial heterogeneity of studies, we did not make the pooling of effect size estimates [24]. Statistical analysis was done with Stata 14 (TX: StataCorp LP). We reported the current systematic review, according to the PRISMA checklist [25] (Additional file 1).

\section{Results}

The four-phase study selection process is presented in Fig. 1. An initial search yielded 1708 citations. Of these, 25 studies were potentially relevant, and a final of 10 studies (with 12 data sets) [10, 12, 26-33] were included in the current review. The agreement between two investigators was substantial (kappa statistics 0.81 ).

The excluded studies were those which did not provide sufficient data on type 1 diabetes mellitus [34-36], did not give a separate data on type 1 diabetes mellitus [37-39], did not assess type 1 diabetes mellitus patients [38-41] or they did assess type 1 diabetes mellitus but not the glucose levels [42-46].

\section{Characteristics of the included studies}

The main characteristics of the included studies are presented in Table 1. These studies included a total of

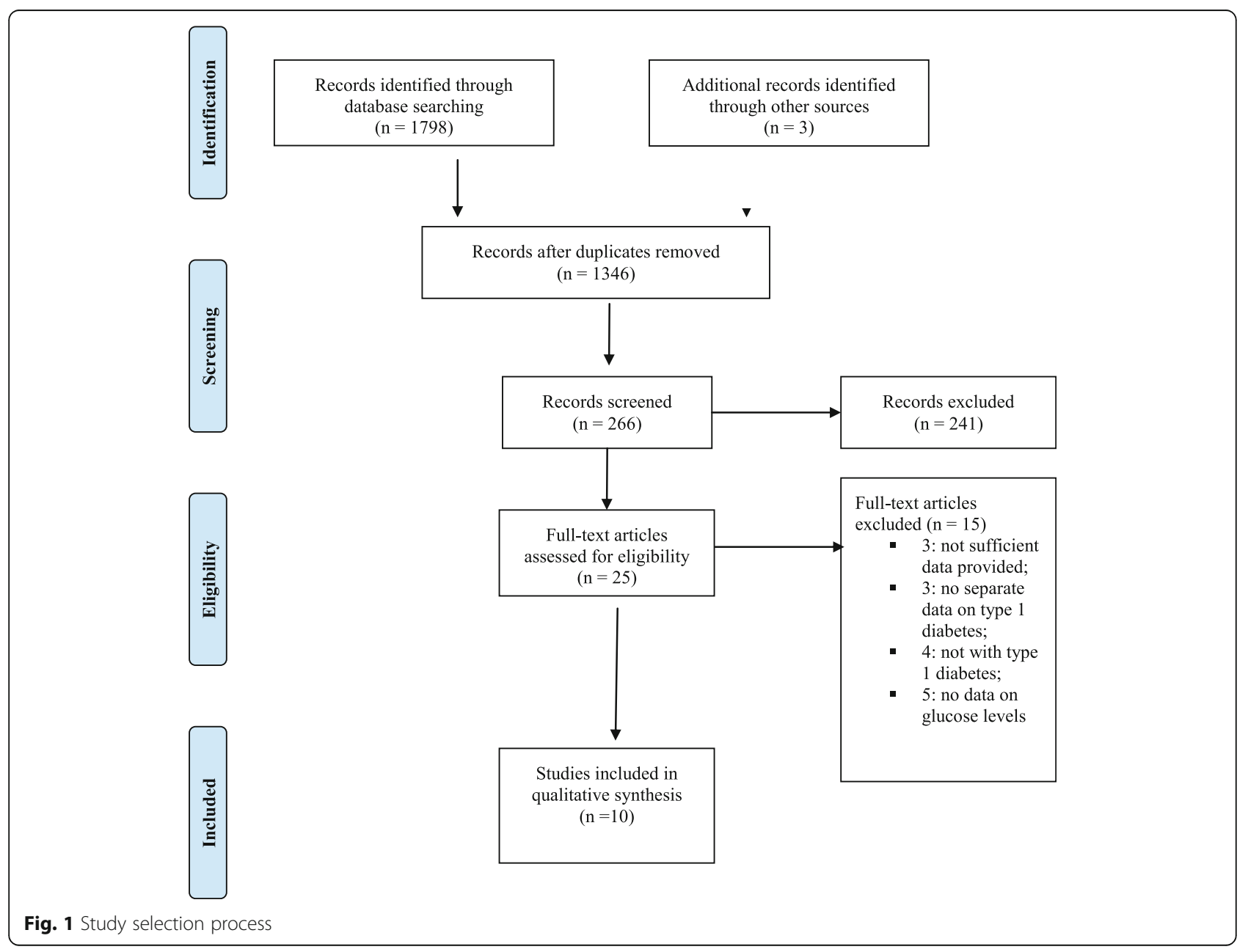


Naing and Max Journal of Diabetes \& Metabolic Disorders (2017) 16:2

Page 4 of 9

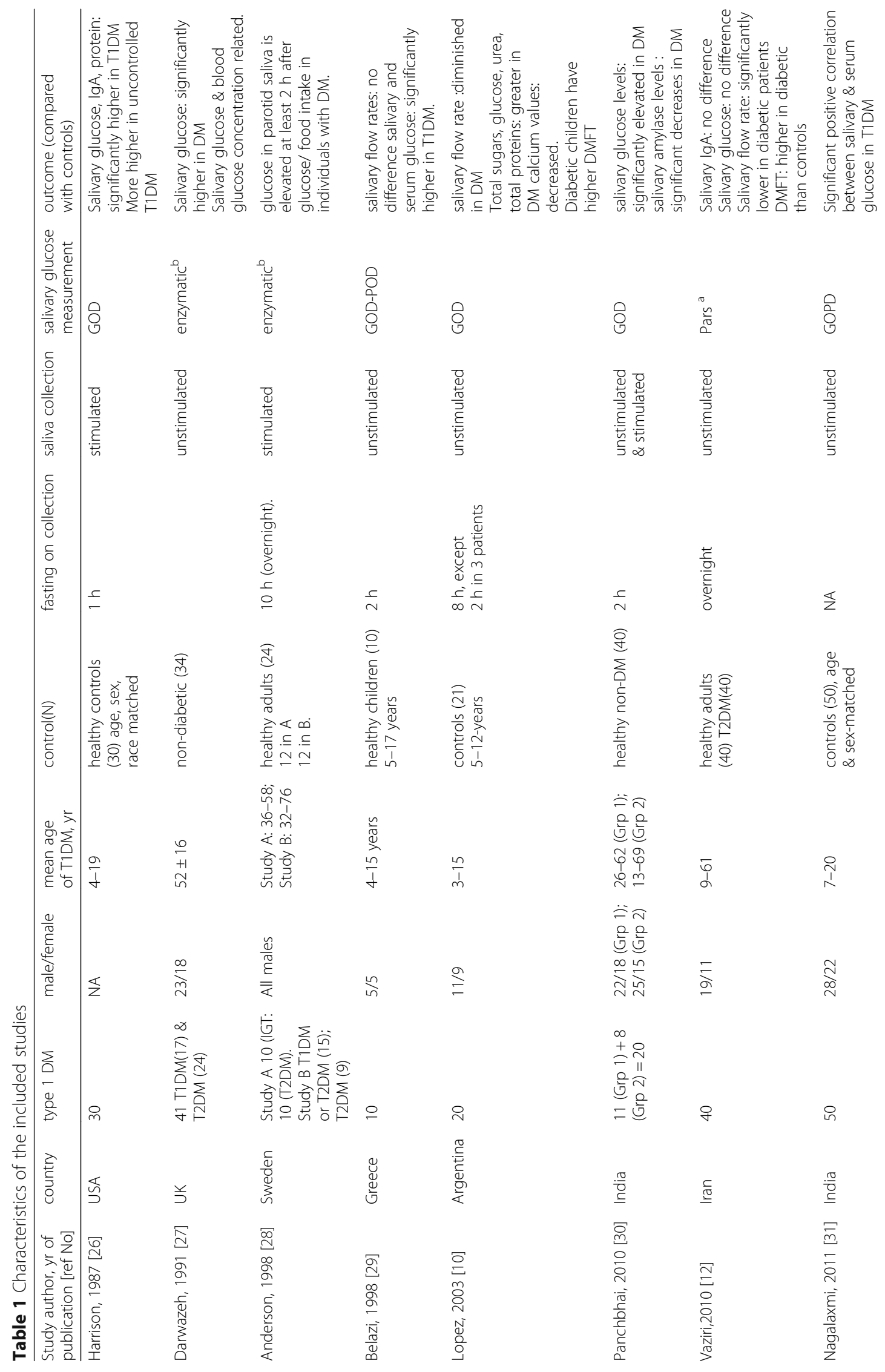


Naing and Max Journal of Diabetes \& Metabolic Disorders (2017) 16:2

Page 5 of 9

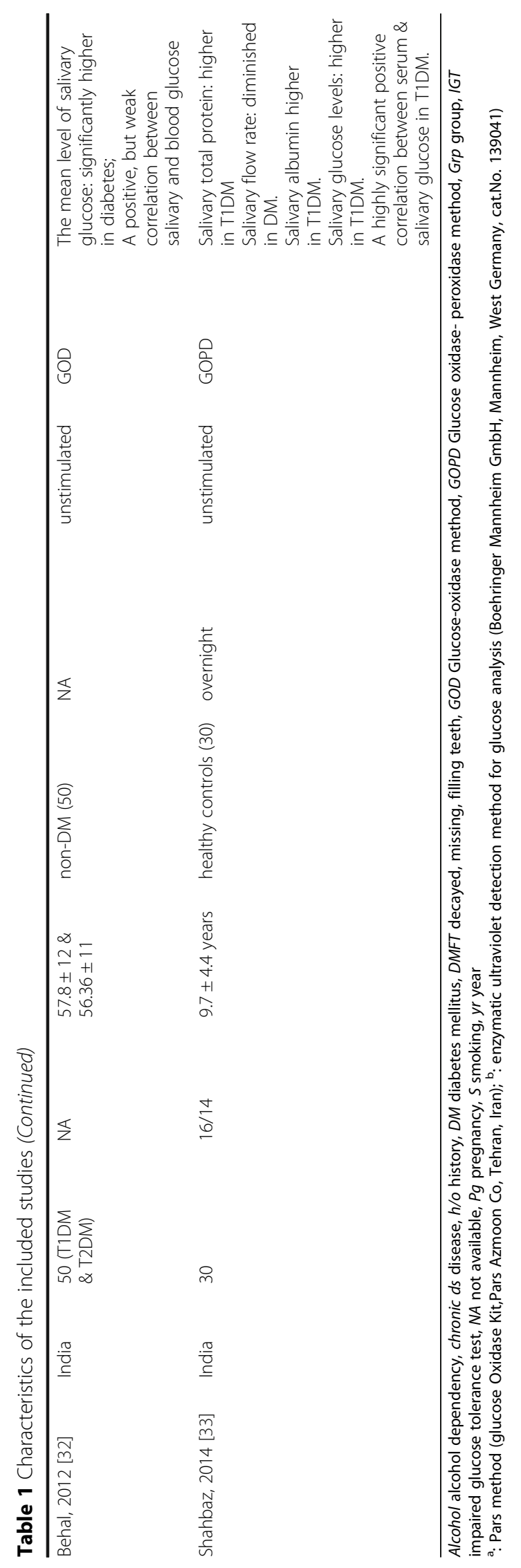


321 cases and 323 controls with ages between 3 and 61 years. Two studies were done exclusively on children with 17 years and below [10, 29]. Eight studies [10, 12, $27-31,33]$ gave data on gender participants and the majority were males $(62 \%, 158 / 255)$.

Four studies were done in India [30-33], and one each in Argentina [10], Greece [29], Iran [12], Sweden [28], the UK [27] and the USA [26]. Seven studies reported information related to blood glucose assessments. Four of these 7 studies (57\%) obtained fasting blood samples [30-33] and measured glucose level with glucose oxidase-peroxidase method (GOPD) [27, 31-33]. For glucose estimations in saliva, four studies used glucose-oxidase method (GOD) [10, 26, 30, 32], three studies used GOPD [29, 31, 33], two studies used enzymatic ultraviolet detection method [27, 28], and the remaining one used kit-based GOD (Pars Azmoon Co, Tehran, Iran). The majority of studies (67\%) collected saliva samples after at least $2 \mathrm{~h}$ of fasting [10, 12, 28-30, 33].

Six studies (8 data sets) reported the significant difference between salivary glucose levels in type 1 diabetes mellitus and controls [10, 12, 26, 29, 30, 33]. Five studies (7 data sets) reported the correlation coefficient between salivary glucose and blood glucose in patients with diabetes [27, 28, 30, 31, 33]. Three studies provided mean differences in two different groups of controls, healthy controls and control population with type 2 diabetes mellitus in one study [10] and poorly controlled/uncontrolled and well controlled/controlled diabetes mellitus in two studies [26, 30].

In general, the methodological quality of these studies were low due to poor quality in performance, reporting or both. Also, these studies failed to do (adequate) follow-up assessments for a stability of their findings. Five of the ten included studies (50\%) in this current review could achieve 5 out of the maximum 9 stars given [10, 26, 27, 30, 31] (Additional file 2).

\section{Effect size}

Two individual studies showed large effect size (Hedge's $g$ 3.75, 95\%CI: 2.9-4.59) [26] and (standardised mean difference, Hedge's $g$ 4.27, 95\%CI: 3.42-5.31) [33]. Due to heterogeneity of studies in view of variation in blood sample collection time and the saliva collection methods, pooling of standardised mean difference represented by Hedge's $g$ index was not attempted. The Harrison study [26] collected blood glucose $1 \mathrm{~h}$ after fasting, while the Shahbaz study [33] used overnight sample. Five studies with exclusively type 1 diabetes mellitus [10, 12, 26, 29, 33 ] reported the mean glucoses levels in saliva and blood and the effect size of each study in terms of Hedge $g$ values were varied from a small effect size $(g=-0.43)$ in the Vaziri study [12] to a substantially higher effect size $(g=4.37)$ in the Shahbaz study [33] (Table 2). Due to substantial heterogeneity of studies, the pooling of effect size was not done. A positive as well as large summary standard mean difference with nonzero overlapping in some of these studies [26, 29, 33] suggested there was some ground to believe that salivary glucose concentrations in the type 1 diabetes mellitus groups were higher than that in the controls.

Five studies reported the correlation between salivary glucose and blood sugar levels in the type 1 diabetes mellitus groups. All these studies showed statistically significant correlations varied from weak positive $(r=0.11)$ to strong positive relationships $(r=0.99)$ (Table 3). Due to a substantial within study heterogeneity, it was not possible to make pooling of studies. Almost perfect relationship between blood and salivary glucose was found in two studies; $r=0.98$ in one study [33] and $r=0.99$ in another study [31].

Two studies $[26,30]$ provided data on those patients with controlled (well controlled) diabetes mellitus as well as those with uncontrolled (poorly controlled) diabetes mellitus. The Harrison study [26] showed that the mean salivary glucose level $(\mathrm{mg} / \mathrm{ml})$ was lower in the healthy controls $(5 \pm 1)$ or good controlled diabetes

Table 2 Distribution of the effect size of the difference between means salivary glucose levels in type 1 diabetes and controls

\begin{tabular}{lccc}
\hline Study [ref] & Effect size, Hedge's $g$ & Lower 95\%Cl & Upper 95\%Cl \\
\hline Shahbaz,2014 [33] & 4.37 & 3.4 & 0.31 \\
Behal, 2012 [32] & 0.48 & 0.09 & 0.87 \\
Panchbhai,2010 $[30]$ & 1.31 & 0.82 & 1.8 \\
Panchbhai,2010 $[30]$ & 1.22 & 0.75 & 1.69 \\
Vaziri,2010 $[12]$ & -0.03 & -0.56 & 0.5 \\
Vaziri,2010 $[12]$ & -0.43 & -0.88 & 0.02 \\
Lopez,2003 [10] & 1.37 & 0.68 & 2.06 \\
Harrison, $1987^{\mathrm{a}}[26]$ & 3.37 & 2.59 & 4.15 \\
Harrison, $1987^{\mathrm{b}}[26]$ & 3.75 & 2.91 & 4.59 \\
Belazi,1998 [29] & 1.3 & 0.34 & 2.26 \\
\hline
\end{tabular}

${ }^{a}:$ controlled or good controlled diabetes mellitus; ${ }^{b}$ : uncontrolled or poorly controlled diabetes mellitus 
Table 3 The relationship between blood and salivary glucose levels in type 1 diabetes

\begin{tabular}{llcl}
\hline Study [Ref] & Sample size & Correlation coefficient & Z score \\
\hline Andersson,1998 [28] & 36 & 0.52 & .5763397 \\
Darwazeh, 1991 [27] & 41 & 0.33 & .3428283 \\
Panchbhai, 2010 [30] & 40 & 0.4 & .0400214 \\
Panchbhai, 2010 [30] & 40 & 0.11 & .1104469 \\
Nagalaxmi, 2011 [31] & 50 & 0.99 & 2.646653 \\
Shahbaz, 2014 [33] & 30 & 0.98 & 2.410142 \\
\hline${ }^{a}$ controlled diabetes mellitus; ${ }^{b}$ uncontrolled diabetes mellitus
\end{tabular}

$(11 \pm 2)$ than the poorly controlled diabetes mellitus of 4-19 years patients $(22 \pm 7)$. The same pattern was found in a study by Panchbhai and associates (30); the mean salivary glucose level $(\mathrm{mg} / \mathrm{ml})$ was lower in the healthy adults $(1.9 \pm 1.4)$ than the controlled $(7.69 \pm 6.4)$ and uncontrolled adult diabetes mellitus (8.1 \pm 6.5$)$. As only two studies provided these information and the age group of participants in these studies varied, we did not make pooling of these studies.

\section{Discussion}

Based on available data, the current meta-analysis provides insights to the utility of saliva in monitoring glycaemia in patients with type 1 diabetes mellitus. Findings suggests that salivary glucose concentrations in the type 1 diabetes mellitus groups were higher than in the controls. Due to a small number of studies with poor methodological quality and variation in reporting of outcome measures, there was no conclusive evidence on the usefulness of salivary glucose concentrations in monitoring glycaemia in type 1 diabetes mellitus.

Saliva contains serumnal components transported from blood capillaries into saliva by diffusion, active transport, and/or ultra- filtration via gingival sulcus. Hence, saliva can serve as a partial filtrate of blood for monitoring the health status of a person [47]. The rationale for the use of saliva in monitoring hyperglycaemia could have many explanations. Glucose is a small molecule which can easily diffuse through semipermeable membranes. The alteration in basement membrane of blood vessels (in patients with diabetes mellitus) leads to increased diffusion of glucose from blood to saliva [33]. Thus, large amounts of glucose concentrate in saliva of patients with diabetes mellitus [21, 26]. Moreover, salivary glands act as filters of blood glucose that would be altered by hormonal or neural regulations $[10,48]$ under several conditions of stress in humans [48]. Hence, salivary glucose level decreased after beginning insulin treatment in both children and adolescents [49], while infections (e.g candidiasis in those with dentures or HIV) and inflammation of salivary glands could increase the glucose level in saliva [31].
The substantial heterogeneity in the current metaanalysis could be due to a diversity in sample selection criteria (stimulated vs unstimulated, fasting hours prior to sample collection), methodological quality of study, underlying comorbid diseases as well as duration of diabetes mellitus and treatment status of diabetes mellitus (poorly controlled or well controlled). For instance, an individual study has shown a higher level of salivary glucose in the poorly controlled group than in the well-controlled group of type 1 diabetes mellitus $(22.0 \pm 7.0 \mu \mathrm{g} / \mathrm{ml}$ vs $11 \pm$ $1 \mu \mathrm{g} / \mathrm{ml}$ ) [26]. Thus far, we are not aware of any studies that provide sensitivity and specificity of salivary glucose levels in monitoring glycaemia in any type of diabetes mellitus. Future studies are required along this line of investigation.

There are some limitations in the present study. Salivary glucose concentration on glycaemia was timedependent as the concentration of glucose in the parotid saliva remains elevated at least $2 \mathrm{~h}$ after glucose/food intake in both normal subjects and persons with diabetes mellitus [28, 37]. Hence the time and method of saliva collection can affect the estimated glucose level. Comorbid conditions could not be ruled out among the participants in the included studies. Many of the included studies were poor in the methodological quality and reliability of the findings is questionable. We did not perform age-specific analysis as there were large differences in the age groups of participants in these studies. This has important implications as the elderly groups are more likely to have other systemic diseases. Only two of ten studies in this meta-analysis were carried out in under 16-year-old children [10, 29]. An interpretation of our results should be aware of these potential confounding factors.

There may be confounding factors in the included studies such as the presence of co-morbidity, compliance to effective treatment, and age difference in participants. Inadequate data do not allow us to perform stratified analyses based on all these influencing factors. Due to the small number of studies with the small sample sizes, the possibility of type II statistical error cannot be ruled out, as the selected studies were not adequately powered to test for differences in the outcomes.

\section{Conclusions}

Findings suggest that salivary glucose concentrations may be helpful in monitoring glycaemia in type 1 diabetes mellitus. However, the clinical utility of using salivary glucose level to monitor glycaemia should be evaluated in future well designed prospective studies. 


\section{Additional files}

Additional file 1: PRISMA checklist. (DOC $59 \mathrm{~kb}$ )

Additional file 2: Table S2. The methodological quality of the included studies. (DOC $53 \mathrm{~kb}$ )

\section{Abbreviations}

ADA: American diabetes association; DM: Diabetes mellitus; GOD: Glucose-oxidase method; GOPD: Glucose oxidase- peroxidase method; IDF: International diabetes federation; NOS: Newcastle-Ottawa scale; PRISMA: Preferred reporting items of systematic review and meta-analysis

\section{Acknowledgements}

The authors are grateful to the participants and researchers of the primary studies in this review. We thank the anonymous reviewers and editors for the comments provided and valuable inputs to improve the quality of manuscript. CN thanks to Drs. Nyunt Wai and Kyan Aung for technical advice on earlier version and to Miss Lai Pei Kuan for helping table formats.

\section{Funding}

None.

\section{Availability of data and material}

Data supporting the results were reported in the manuscript.

\section{Authors' contributions}

JWM conceptualized, assisted in study design and write-up; CN developed study design, collected data, analysed data and wrote the first draft. Both authors revised the manuscript. Both authors read and approved the final manuscript.

\section{Competing interests}

The authors declare that they have no competing interests.

\section{Consent for publication}

Not applicable.

\section{Ethics approval and consent to participate}

Ethics approval and consent were waived by the Joint Research and Ethics Committee at the International Medical University in Kula Lumpur of Malaysia as this study was exclusively performed with the published data.

Received: 24 October 2016 Accepted: 14 January 2017

Published online: 21 January 2017

\section{References}

1. ADA (The American Diabetes Association). Diagnosis and classification of diabetes mellitus. Diabetes Care. 2015;38:S8-S16. http://care diabetesjournals.org/content/38/Supplement_1/S8. Accessed 12 May 2016

2. IDF (International Diabetes Federation). Diabetes atlas. 2015. http://www. diabetesatlas.org/resources/2015-atlas.html. Accessed 2 May 2016.

3. Patterson CC, Dahlquist GG, Gyurus E, Green A, Soltesz G. Incidence trends for childhood type 1 diabetes in Europe during 1989-2003 and predicted new cases 2005-20: a multicentre prospective registration study. Lancet. 2009:373:2027-33.

4. Simmons $\mathbf{J H}$, et al. Reliability of the diabetes fear of injecting and self-testing questionnaire in paediatric patients with type 1 diabetes Diabetes Care. 2007;30:987-8.

5. Wright S, Yelland M, Heathcote K, Ng SK, Wright G. Fear of needles-nature and prevalence in general practice. Aust Fam Physician. 2009;38:172-6.

6. Chiasson $J$, Morrisset $R$, Hamet P. Precision and costs of techniques for self-monitoring of serum glucose levels. Can Med Assoc J. 1984;130:38-43.

7. Soukup M, Biesiada I, Henderson A, Idowu B, Rodeback D, Ridpath L, Bridges EG, Nazar AM, Bridges KG. Salivary uric acid as a noninvasive biomarker of metabolic syndrome. Diabetol Metab Syndr. 2012:4:14.

8. Raggam RB, Wagner J, Michelin BDA, Putz-Bankuti C, et al. Reliable detection and quantitation of viral nucleic acids in oral fluid: liquid phase-based sample collection in conjunction with automated and standardized molecular assays. J Med Virol. 2008;80:1684-8.
9. Rathnayake N, Åkerman S, Klinge B, Lundegren N, Jansson H, Tryselius Y, et al. Salivary biomarkers for detection of systemic diseases. PLoS One. 2013; 8(4):e61356

10. Lopez ME, Colloca ME, Paez RG, Schallmach JN, Koss MA, Chervonagura A Salivary characteristics of diabetic children. Braz Dent J. 2003;14:26-31.

11. Amer S, Yousuf M, Siddqiui PQ, Alam J. Salivary glucose concentrations in patients with diabetes mellitus - a minimally invasive technique for monitoring blood glucose levels. Pak J Pharm Sci. 2001;14:33-7.

12. Vaziri PB, Vahedi M, Mortazavi H, Abdollahzadeh S, Hajilooi M. Evaluation of salivary glucose, IgA and flow rate in diabetic patients: a case-control study. J Dent (Tehran). 2010;7:13-8.

13. Mascarenhas P, Fatela B, Barahona I. Effect of diabetes mellitus type 2 on salivary glucose - a systematic review and meta-analysis of observational studies. PLoS One. 2014;9:e101706.

14. Al-Tarawneh SK, Border BM, Dibble FC, Bencharit S. Defining salivary biomarkers using mass spectrometry-based proteomics: a systematic review. OMICS. 2011:15:353-61.

15. Nunes LAS, Mussavira S, Bindhu OS. Clinical and diagnostic utility of saliva as a non-invasive diagnostic fluid: a systematic review. Biochem Med (Zagreb). 2015;25:177-92.

16. Bertoluci MC, Ce GV, da Silva AM, Wainstein MV, Boff W, Punales M. Endothelial dysfunction as a predictor of cardiovascular disease in type diabetes. World J Diabetes. 2015;6:679-92.

17. Moher D, Liberati A, Tetzlaff J, Altman DG, Group PRISMA. Preferred reporting items for systematic reviews and meta-analyses: the PRISMA statement. PLoS Med. 2009;6.

18. ADA (The American Diabetes Association). Standard of medical care in diabetes. 2014. http://care.diabetesjournals.org/content/37/Supplement_1/ S14.extract. Accessed 2 Mar 2016

19. Wells GA, Shea B, O'Connell D, et al. The Newcastle-Ottawa scale (NOS) for assessing the quality of non-randomised studies in meta-analyses. Ottawa: Ottawa Hospital Research Institute; 2011. http://www.ohri.ca/programs/ clinical_epidemiology/oxford.asp. Accessed 12 Jan 2016.

20. Borenstein M, Hedges VL, Higgins PTJ, Rothstein RH. Introduction to metaanalysis. West Sussex, UK: John Wiley and Sons Ltd; 2009.

21. Ellis PD. Effect size equation 2009 http//www polyu edu hk/mm/ effectsizefaqs/effect_size_equations2.html. Accessed 11 Jan 2015.

22. Cohen J. Statistical power analysis for the behavioural sciences. Curr Dir Psychol Sci. 1992;1:98-101. http://courses.csusm.edu/psyc393md/2012Spring-20950/readings/StatisticalPower/Cohen\%281992\%29StatisticalPower. pdf. Accessed 27 Feb 2016.

23. Coe R. It is the effect size, stupid. In: What effect size and why it is important 2002. http://www.cem.org/attachments/ebe/ESguide.pdf. Accessed 12 May 2016.

24. Higgins JPT, Green S, eds. Cochrane Handbook for Systematic Reviews of Interventions Version 5.1.0 (updated March 2011). The Cochrane Collaboration; 2011. www.cochranehandbook.org. Accessed 4 Jan 2016.

25. Liberati A, Altman DG, Tetzlaff J, Mulrow C, Gøtzsche PC, loannidis JP, et al. The PRISMA statement for reporting systematic reviews and meta-analyses of studies that evaluate healthcare interventions: explanation and elaboration. BMJ. 2009;339:b2700

26. Harrison $\mathrm{R}$, Bowen WH. Flow rate and organic constituents of whole saliva in insulin-dependent diabetic children and adolescents. Pediatr Dent. 1987:9:287-91.

27. Darwazeh AM, MacFarlane TW, McCuish A, Lamey PJ. Mixed salivary glucose levels and candidal carriage in patients with diabetes mellitus. J Oral Pathol Med. 1991;20:280-3.

28. Andersson BA, Birkhed D, Berntorp K, Lindgarde F, Matsson L. Glucose concentration in parotid saliva after glucose/food intake in individuals with glucose intolerance and diabetes mellitus. Eur J Oral Sci. 1998;106:931-7.

29. Belazi MA, Galli-Tsinopoulou A, Drakoulakos D, Fleva A, Papanayiotou PH. Salivary alterations in insulin-dependent diabetes mellitus. Int J Paediatr Dent. 1998:8:29-33.

30. Panchbhai AS, Degwekar SS, Bhowte RR, Degweka SS. Estimation of salivary glucose, salivary amylase, salivary total protein and salivary flow rate in diabetics in India. J Oral Sci. 2010;52:359-68.

31. Nagalaxmi $\vee$, Priyanka V. Can saliva be a marker for predicting type 1 diabetes mellitus? - a pilot study. J Indian Acad Oral Med Radiol. 2011;23:579-82.

32. Behal S, Lele S. Correlation of salivary glucose with blood glucose in diabetic individuals. Indian J Stomatol. 2012;3:212-6.

33. Shahbaz S, Katti G, Ghali SR, Katti C, Diwakar DD, Guduba V. Salivary alterations in type 1 diabetes mellitus patients: salivary glucose could be 
noninvasive tool for monitoring diabetes mellitus. Indian J Dent Res. 2015;25:420-4. http://www.ijdr.in/text.asp?2014/25/4/420/142512. Accessed 18 Mar 2016.

34. Mata AD, Marques $D$, Rocha $S$, et al. Effects of diabetes mellitus on salivary secretion and its composition in the human. Mol Cell Biochem. 2004;261:137-42.

35. Veleganova VK, Kondeva VK, Uzunova YI, Simitchiev KK. Salivary status of diabetic children. J Int Sci Publ. 2014;12. http://www.scientific-publications. net/get/1000008/1409886727315935.pdf. Accessed 22 May 20156.

36. Abikshyeet $P$, Ramesh V, Oza V. Glucose estimation in the salivary secretion of diabetes mellitus patients. Diabetes Metab Syndr Obes Targets Ther. 2012;5:149-54.

37. Jurysta C, Bulur N, Oguzhan B et al. Salivary glucose concentration and excretion in normal and diabetic subjects. J Biomed Biotechnol. 2009;6.

38. Lasisi TJ, Fasanmade AA. Salivary flow and composition in diabetic and non-diabetic subjects. Niger J Physiol Sci. 2012;27:79-82.

39. Barnes MV, Kennedy DA, Panagakos F et al. Global metabolomic analysis of human saliva and plasma from healthy and diabetic subjects, with and without periodontal disease. PLoS One. 2014;9:e105181. Correction in: PLoS One 9: e114091.

40. Forbat LN, Collins RE, Maskell GK, Sonksen PH. Glucose concentrations in parotid fluid and venous blood of patients attending a diabetic clinic. J R Soc Med. 1981;74:725-8.

41. Sandberg GE, Sundberg HE, Fjellstrom CA, Wikblad KF. Type 2 diabetes and oral health: a comparison between diabetic and non-diabetic subjects. Diabetes Res Clin Pract. 2000:50:27-34.

42. Azizi A, Modaberi A. The correlation of blood glucose with salivary glucose level in diabetic patients. J Islamic Dent Assoc IRAN (JIDA) Winter. 2014; 25(4). http://applications.emro.who.int/imemrf/J_Islam_Dent_Assoc_Iran/J_ Islam_Dent_Assoc_Iran_2014_25_4_337_340.pdf. Accessed 28 March 2016

43. Vasconcelos ACU, Soares MSM, Almeida PC, Soares TC. Comparative study of the concentration of salivary and blood glucose in type 2 diabetic patients. J Oral Sci. 2010;52:293-8.

44. Moore PA, Weyant RJ, Etzel KR, et al. Type 1 diabetes mellitus and oral health: assessment of coronal and root caries. Community Dent Oral Epidemiol. 2001;29:183-94.

45. Moreira AR, Passos IA, Sampaio FC, Soares MS, Oliveira RJ. Flow rate, pH and calcium concentration of saliva of children and adolescents with type 1 diabetes mellitus. Braz J Med Biol Res. 2009;42:707-11.

46. Collin HL, Uusitupa M, Niskanen L, Koivisto AM, Markkanen H, Meurman JH. Caries in patients with non-insulin-dependent diabetes mellitus. Oral Surg Oral Med Oral Pathol Oral Radiol Endod. 1988;85:680-5.

47. Khanna P, Walt DR. Salivary diagnostics using a portable point-of-service platform: a review. Clin Ther. 2015;37:498-504.

48. Chatterton Jr RT, Vogelsong KM, Lu YC, Ellman AB, Hudgens GA. Salivary alpha-amylase as a measure of endogenous adrenergic activity. Clin Physiol. 1996;16:433-48.

49. Karjalainen KM, Knuuttila ML, Kaar ML. Salivary factors in children and adolescents with insulin-dependent diabetes mellitus. Pediatr Dent. 1996;18:306-11.

\section{Submit your next manuscript to BioMed Central and we will help you at every step:}

- We accept pre-submission inquiries

- Our selector tool helps you to find the most relevant journal

- We provide round the clock customer support

- Convenient online submission

- Thorough peer review

- Inclusion in PubMed and all major indexing services

- Maximum visibility for your research

Submit your manuscript at www.biomedcentral.com/submit

) Biomed Central 